\title{
SACERDOTISAS Y DEVOTAS EN LA HISPANIA ANTIGUA: UN ACERCAMIENTO ICONOGRÁFICO
}

\section{PRIESTESSES AND DEVOTEES IN HISPANIA ANTIGUA: ICONOGRAPHIC APPROACH}

\author{
MERCEDES ORIA SEGURA*
}

\begin{abstract}
Resumen: Las mujeres hispanorromanas intervinieron de forma activa en la vida religiosa de sus comunidades, actuando como sacerdotisas o bien como simples devotas. La forma de expresión de unas y otras difiere debido a su desigual relevancia pública. Las sacerdotisas fueron frecuentemente honradas con estatuas, cuya iconografía desconocemos por no haberse conservado imágenes asociadas a sus dedicatorias inscritas, aunque podemos relacionarlas con algunos modelos escultóricos conocidos. Pero en realidad, sólo conservamos muy pocas imágenes de carácter genérico y de iconografía no siempre clara. En cuanto a las devotas, no han dejado representaciones figurativas de sí mismas. Sólo la epigrafía nos permite caracterizar su actitud discreta frente a los dioses, casi siempre vinculadas de forma expresa a los hombres de su familia, aunque también en ciertos casos la ostentación de sus exvotos las hace plenamente visibles aunque de forma indirecta.
\end{abstract}

Palabras clave: Sacerdotisas, devotas, Hispania, imagen pública.

Con toda oportunidad y merecimiento, el Departamento de Prehistoria y Arqueología de la Universidad de Sevilla rinde en este volumen de la revista Spal un homenaje a una de las primeras figuras de la Arqueología española, el catedrático de la Universidad Autónoma de Madrid Prof. D. Manuel Bendala Galán, cuyos estrechos vínculos con nuestro Departamento, y en particular con quien esto suscribe por razones que van mucho más allá de lo profesional ${ }^{1}$, no es necesario reiterar.

\footnotetext{
* Universidad de Sevilla

1. Me gustaría recordar aquí también a sus padres, mis tíosabuelos Antonio y Pepa, tan queridos en la familia Oria Bendala e
}

\begin{abstract}
Hispano-Roman women intervened actively in the religious life of their communities, acting as priestesses or as simple devotees. The ways of expression differ from one group to the other, due to their unequal public relevance. The priestesses were often honoured with statues, but we don't know their actual appearance because the sculptures associated with the inscribed dedications are not preserved. Anyway we can relate them to some known sculptural models. But in reality, we only keep very few generic images whose iconography is not always clear. In the case of the devotees, they haven't left figurative representations of themselves. Epigraphy only allows us to characterize their low profile before the gods and their close links with their male relatives, although in some cases the display of their votive offerings makes them fully visible, even indirectly.
\end{abstract}

Key words: Priestesses, devotees, Hispania, public image.

Como no podía ser menos, me adhiero al mismo con un trabajo que estoy segura de que a él, como gran conocedor de las religiones de la Hispania antigua, le interesará.

Podría describirse el panorama religioso de Hispania como un mosaico de formas de culto, en el que tradiciones prerromanas de diferentes orígenes y gran antigüedad son parcialmente encubiertas por una religión oficial de origen foráneo, la romana, que integra también con el tiempo otros cultos genéricamente

indisolublemente asociados a tantos veranos de infancia y juventud en la costa de Huelva. 
conocidos como "orientales". El elemento femenino tiene una importante presencia en este conjunto, bien sea como objeto de culto, como oficiante del mismo o simplemente como devota. Sin embargo, no todas estas facetas son igualmente visibles según los testimonios que conservamos de las mismas. La desigualdad se acentúa cuando nos movemos en el terreno de las imágenes. Si la documentación visual sobre las diosas conocidas por los hispanos es abundante ${ }^{2}$, no podemos decir lo mismo de las otras protagonistas femeninas de la religión. Repasaremos aquí las escasas representaciones conocidas de sacerdotisas y devotas hispanas, que nos suscitan algunas reflexiones.

\section{LAS SACERDOTISAS}

\section{I.1. Las actividades cultuales de las mujeres romanas}

Teóricamente, la capacidad de las romanas para ser sacerdotisas está limitada tanto por su escasa actividad pública, como por antiquísimas normas rituales. Sin embargo en la práctica hay numerosas excepciones que afectan precisamente a funciones sacerdotales oficiales, aunque reputados especialistas en la religión romana (con afirmaciones continuas en ese sentido, Scheid 1991) los han presentado como situaciones excepcionales en las que las mujeres asumen papeles masculinos. Como indicamos en otro trabajo (Oria e.p.), donde incluimos abundantes referencias bibliográficas y un catálogo de 91 imágenes de sacerdotisas de todo el Imperio Romano, documentos de todo tipo y en particular los iconográficos demuestran lo injustificado de esta postura. Resumimos aquí brevemente sus argumentos, remitiendo al mismo para su desarrollo completo:

- Las mujeres romanas desempeñan un repertorio relativamente limitado, pero bien definido de sacerdocios y en la mayor parte de los casos lo hacen a título individual y no como esposas de un sacerdote, aunque también pueda darse esta situación.

2. Se encuentra en prensa nuestra contribución al I Encuentro Nacional de Iconografia en el Mundo Antiguo: La sociedad a través de la imagen, celebrado en Madrid en abril de 2010, donde hacemos un repaso de las diosas atendiendo a los conceptos de feminidad que representan (Oria, 2011). El presente trabajo lo complementa desde el punto de vista de las mujeres "terrenales" que intervienen en el culto. Ambos se realizan en el marco del proyecto de investigación "Construyendo una imagen. Política y género en la propaganda en la Antigüedad: precedentes y legado", HAR2008-01368/HIST del Ministerio de Ciencia e Innovación.
- Sirven con preferencia a diosas, con muy pocas excepciones, pero no por fuerza atendiendo a sus facetas más tópicamente femeninas. Por el contrario, su papel más activo lo ejercen en el terreno de los cultos cívicos y de forma muy destacada en el imperial.

- La iconografía es abundante, afecta a todo tipo de sacerdocios y cultos y las muestra interviniendo en rituales variados, incluidos los sacrificios animales, sin más limitaciones en estos últimos que la que comparten con los sacerdotes masculinos: no ejecutar personalmente a la víctima.

Nuestra información respecto a las sacerdotisas hispanas se basa casi únicamente en la epigrafía. Sólo en CIL II hay 73 menciones a sacerdotisas de cultos oficiales, cifra que en los últimos tiempos se ha reducido a 72 (Hoyo 2003: 130-131, Cuadro 1 con el reparto por cargos y provincias) al descartarse varias de ellas y añadirse otras de reciente aparición. Los cargos mencionados son básicamente dos. El de flaminica existe probablemente desde época de Tiberio como su equivalente masculino y está constatado hasta la primera mitad del siglo III, como fenómeno propio de las provincias occidentales aunque no de Roma (Delgado 1998: 73, Hemelrijk 2006: 180). Habitualmente es ejercido por damas de la alta sociedad provincial que sin embargo, no siempre ni mucho menos son las esposas de los $f l a-$ mines. Junto a ellas, proliferan en Hispania las mujeres con el título más genérico de sacerdos, que ejercen en relación con divinidades muy variadas. Se conoce incluso una "ministra de Tutela Augusta", que se presenta como esposa de un sevir (CIL II 3349, de Mancha Real, Jaén). Es un puesto secundario cuya función principal se relaciona con el mantenimiento de los recintos cultuales y la organización de las ceremonias (Schultz 2006: 70) que puede ser ejercido por libertas, condición de este matrimonio hispano que parece reproducir en su escala social el esquema propio de los sacerdocios ciudadanos reservados a los estratos dirigentes.

\section{I.2. Los precedentes: las sacerdotisas prerromanas}

Prácticamente no conservamos imágenes de sacerdotisas romanas en Hispania. Esto resulta un tanto sorprendente, ya que las religiones prerromanas con mayor tradición iconográfica, en particular la ibérica, nos muestran diversos ejemplos de mujeres con funciones sacerdotales o al menos interviniendo en rituales. Así dentro del ámbito púnico, donde las sacerdotisas son bien conocidas por testimonios epigráficos e incluso 
pertenecen a la realeza (numerosos ejemplos en Jiménez 2006: 84-87), algunas figuras pueden identificarse por su vestimenta y atributos como sacerdotisas de extracción social elevada, caso de dos terracotas de Puig des Molins (Ibiza) (Jiménez 2006: 89). Las jóvenes desnudas pero enjoyadas, con peinado hathórico, representadas con cierta frecuencia en piezas occidentales de bronce como exvotos, timiaterios (el de La Quéjola, publicado por Fernández Miranda y Olmos 1987: 215 216, Figs. 2-3, es un ejemplo hispano bien conocido) y objetos similares, se relacionan también con el culto aunque más bien en calidad de "servidoras", hieródulas o prostitutas sagradas, que propiamente de sacerdotisas dentro de una estructura fuertemente jerarquizada (Negri Scafa 2001: 395; sobre la prostitución sagrada ligada al culto de Astarté y Tanit, Lipinski 1992, Ribichini 2004).

La existencia de sacerdotisas en el mundo ibérico se presupone por la presencia de divinidades femeninas en su panteón y los paralelos con situaciones semejantes en el resto del Mediterráneo (Chapa-Madrigal 1997: 188 ss., esp. 192). Como sus equivalentes masculinos, estas mujeres pertenecerían a las élites sociales de sus respectivas comunidades. A su vez la iconografía ibérica, tan abundante como expresiva, incluye numerosas figuras de mujer con vestimentas y actitudes que podemos calificar de ceremoniales. Diversos autores han propuesto identificar a sacerdotes y sacerdotisas a partir de una serie de rasgos como la tonsura, las mitras, los mantos echados sobre el hombro izquierdo, las túnicas rematadas en volantes y con aberturas laterales, collares de lengüetas y brazaletes en espiral (Nicolini 1998: 249; Moneo 2003: 383, con referencias anteriores) ${ }^{3}$. Esa indumentaria la encontramos tanto en figurillas de pequeño tamaño como en la estatuaria mayor. $\mathrm{Su}$ riqueza (joyas abundantes, gruesos tejidos decorados) corrobora el elevado nivel económico de quienes las ostentan. Lo que no nos indica la iconografía es la función ritual concreta desempeñada por estas sacerdotisas, ya que al menos en el conjunto de exvotos de Despeñaperros se muestran preferentemente estáticas y con los brazos caídos a los lados del cuerpo (Prados 1997: 276). Chapa y Madrigal (1997: 195) se inclinan por relacionar con sacerdotisas las figuras de damas sedentes con las manos sobre las rodillas del Cerro de los Santos, que aludirían a la diosa allí venerada bien directamente, bien mediante representaciones en

3. Ver un resumen de las diferentes posiciones acerca de la identificación de los sacerdotes ibéricos, con referencias bibliográficas en Chapa 2006: 157-158. las que sus sacerdotisas se identificasen con ella, pero tampoco en estos casos se ejecuta un acto ritual preciso. La Dama de Baza, urna cineraria monumental de una mujer adulta, plantearía la misma situación: iconografía divina con la que se identifica una dama de alto standing, que sin embargo hasta ahora no ha sido claramente considerada como sacerdotisa (v. Bendala 2007 y en general, el resto de los trabajos incluidos en ChapaIzquierdo 2007). Por otra parte tampoco han aparecido hasta ahora elementos con connotaciones rituales y sacrificiales, como los cuchillos curvos, asociados a tumbas femeninas (Chapa-Madrigal 1997: 192-193).

Pese a todo ello las presuntas sacerdotisas prerromanas, o las servidoras del culto si se prefiere un término más genérico que permita incluir más variedad de funciones, se presentan habitualmente como tales, bien sea por su vestimenta (damas ibéricas) o total carencia de ella (figuras juveniles orientalizantes), por realizar un gesto ritual preciso como portar una ofrenda ("damas oferentes" de los santuarios ibéricos, relieve de Osuna con oferentes: García y Bellido 1943: 25, Chapa 1997: 29 ss., y relieve de Torreparedones: Serrano Morena 1988: 247-248, Figs. 3-4), o tocar un instrumento musical (La Serreta de Alcoy: Marín 2000-2001: 189, Lám. 6; Osuna, relieve de la auletris: García y Bellido 1943: 25, Chapa 1997: 29 ss.), o por encontrarse dentro del marco físico del santuario (Torreparedones: Serrano - Morena 1988: 247-248, Figs. 3-4). O quizás más bien deberíamos decir que, en unos códigos figurativos en los que no parece existir la noción de retrato personal, si reconocemos como sacerdotisa a una determinada imagen de mujer es porque sus atributos y gestos son de manera genérica los de esa categoría social y religiosa. Por el contrario, en el mundo romano hay numerosos retratos que no reconoceríamos como tales sacerdotisas si no fuera por la indicación escrita que los acompaña, aunque no es ni mucho menos el único caso posible.

\section{I.3. Las sacerdotisas romanas}

En Hispania, la excepción más clara es una figurilla de la provincia de Zamora, en concreto del Pago de Alba en la localidad de Villalazán (Fig. 1), que ha sido publicada como Abundantia y como una variante de Fortuna, aunque sugiriendo su relación con iconografías sacerdotales (Bronces... 1990: 240 n 145; García Rozas-Abásolo 1993: 181-184). Muestra a una dama con túnica ceñida a la altura de las caderas donde se pliega en forma abolsada, que cae en amplios pliegues 


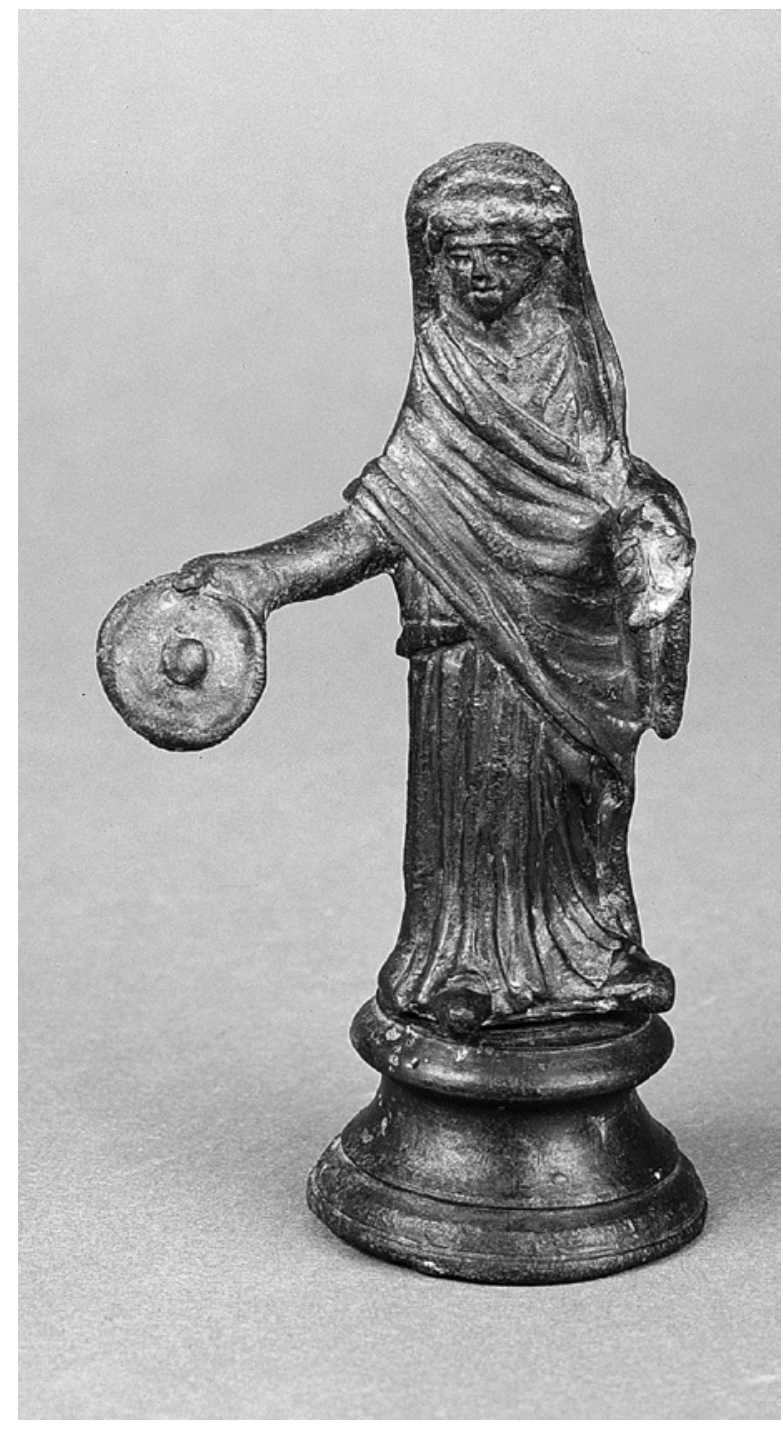

Fig. 1: Figurilla de bronce con representación de sacerdotisa realizando una libación, siglos I-II d.C. Pago de Alba, Villalazán (Zamora) (Foto Museo de Zamora, Junta de Castilla y León).

hasta los pies, de los que sólo asoman las puntas con calzado cerrado puntiagudo. Se le superpone un manto que envuelve los hombros y sujeta uno de sus lados en el brazo izquierdo; desde el hombro derecho cruza el pecho en diagonal a la cadera izquierda y sube por la espalda hasta cubrir la cabeza, cayendo el otro extremo sobre el hombro derecho. En la cabeza, bajo el manto, se advierte claramente una gruesa diadema superpuesta a los mechones ondulados de la frente, aunque no es posible distinguir decoración alguna en ella. No se aprecian en cambio otras joyas como pendientes o collares. Adelanta la mano derecha con una pátera en el gesto de ofrecer una libación. El brazo izquierdo flexionado con la mano adelantada también sostuvo otro objeto hoy desaparecido, quizás la acerra, la cajita de la que se extrae el incienso, u otro similar. Brazos y manos son desproporcionadamente grandes respecto al cuerpo, como si quisiera destacar sus gestos.

El de la libación es precisamente el gesto cultual más repetido en imágenes de sacerdotisas de todo el Imperio, cuando se muestran en el ejercicio de su función. Los paralelos son numerosos tanto en figurillas semejantes como en estatuaria mayor y entre ellos podríamos citar, simplemente a título de ejemplo, la sacerdotisa del macellum de Pompeya (Bonifacio 1977: 53-56 n ${ }^{\circ} 12$ ), la difunta Laberia Felicla cuyo relieve se conserva en los Museos Vaticanos (Vermaseren 1977: 6869, Lám. CL), o la Livia que acompaña a Augusto y a un joven príncipe de la familia en el altar de los Lares de Augusto encontrado en el Vicus Sandaliarius y conservado en la Galleria degli Uffizzi de Florencia (Holscher 1994: 162 Lám. 29; Bert Lott 2004: 144-146). Más aún, es una actitud ya documentada en imágenes de sacerdotisas del ámbito cultural etrusco fechadas entre los siglos III-II a.C. (pueden verse ejemplos en Cristofani 1985: 174-182, $n^{\circ}$ 68-71, 76-78), de las que estos pequeños bronces parecen derivar. Sirva como ejemplo una figurilla conservada en la Hispanic Society of America ( $\mathrm{n}^{\circ}$ inv. D923), que apenas se diferencia de la pieza zamorana más que en el arcaísmo de los rasgos, en la forma del tocado y en la posición del manto recogido a la altura de las caderas (Fig. 2) ${ }^{4}$. El bronce que ahora describimos es lógicamente una representación genérica, de escasa calidad aunque con cierta riqueza de detalles sobre todo en el rostro, encaminada a sugerir la ocupación de su propietaria o dedicante.

Menos evidente es una estatuilla de matrona velada, quizás con una corona de flores bajo el velo (Fig. 3), aparecida en el Cerro del Calvario de Mérida hace cerca ya de un siglo asociada a un togado y a otra figura de hombre joven. En su momento Mélida (1925: 319-320) los interpretó como los Genios de un matrimonio, la "Juno"

4. En nuestro trabajo en prensa (Oria e.p.) recogíamos como hispana, con el $n^{\circ}$ 68, esta pieza publicada en Tesoros HSA 2009: 405 $\mathrm{n}^{\circ} 48$. Dicho catálogo le atribuía tal procedencia por ser la más habitual entre las piezas de la antigua Colección Vives, a la que previamente perteneció, y la fechaba entre los siglos II-III d.C. Un análisis posterior más detenido nos ha confirmado su estrecha coincidencia con piezas etruscas como las citadas (particularmente cercano el $\mathrm{n}^{\mathrm{o}} 77$ de Cristofani 1985). Las circunstancias de su llegada a la Colección Vives, procedente del mercado anticuario, son compatibles con una compra original en Italia. 


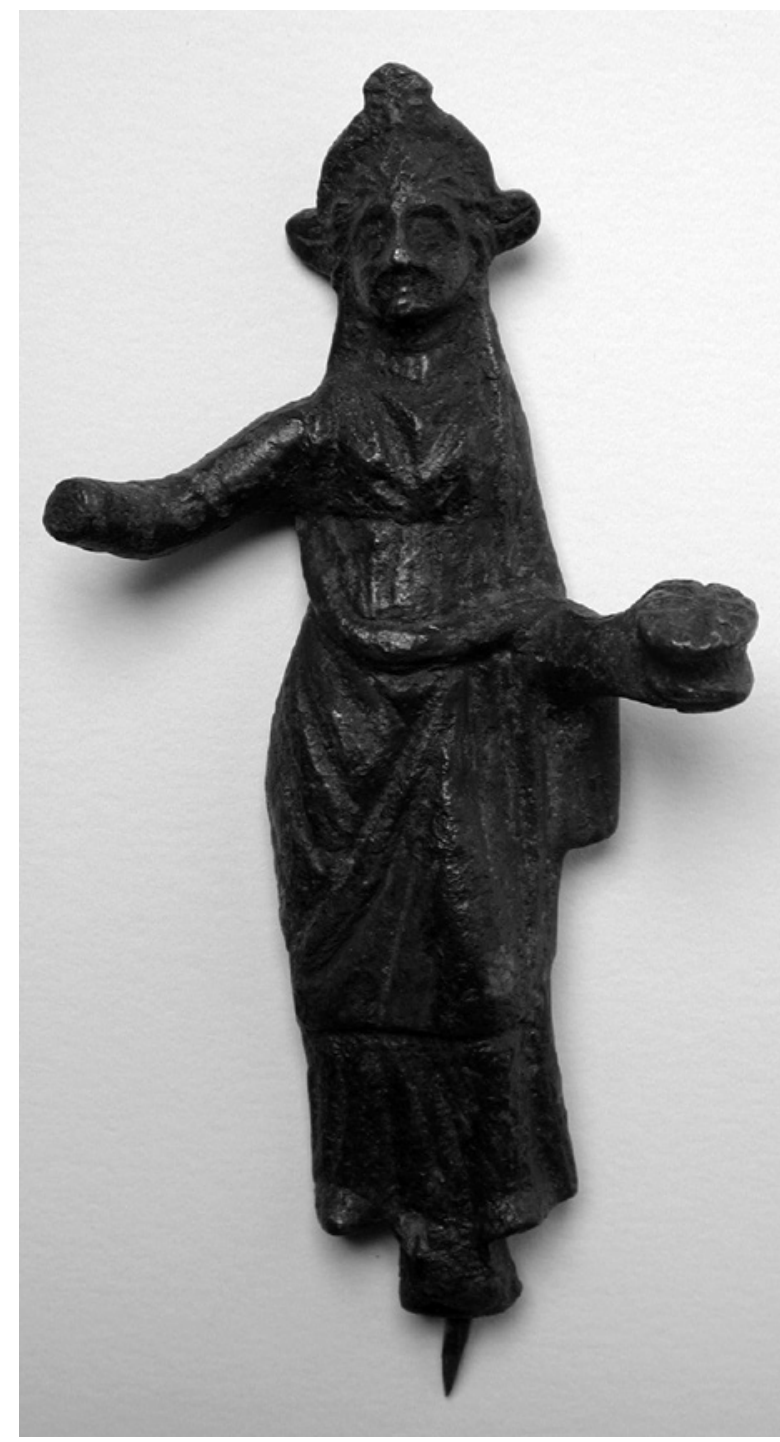

Fig. 2: Figura etrusca de sacerdotisa en actitud sacrificial, siglo II a.C. Procedencia itálica indeterminada (Foto Hispanic Society of America).

de la esposa en el caso de la figura femenina. Más recientemente Mirón (1996: 185) los considera una pareja de sacerdotes, flamen y flaminica. La identificación descansa en esta ocasión sobre bases menos sólidas, ya que la corona floral, un elemento presente en imágenes de sacerdotisas como la pompeyana antes citada y la dama madura del British Museum ( $\left.n^{\circ} 1873,0820.741\right)$, no es claramente visible. Tampoco lleva en las manos objetos rituales como la anterior, aunque la posición de las mismas es ciertamente peculiar: la izquierda adelantada a la altura de la cadera cierra el puño aunque sugiriendo el hueco para sujetar un objeto estrecho y alargado; la

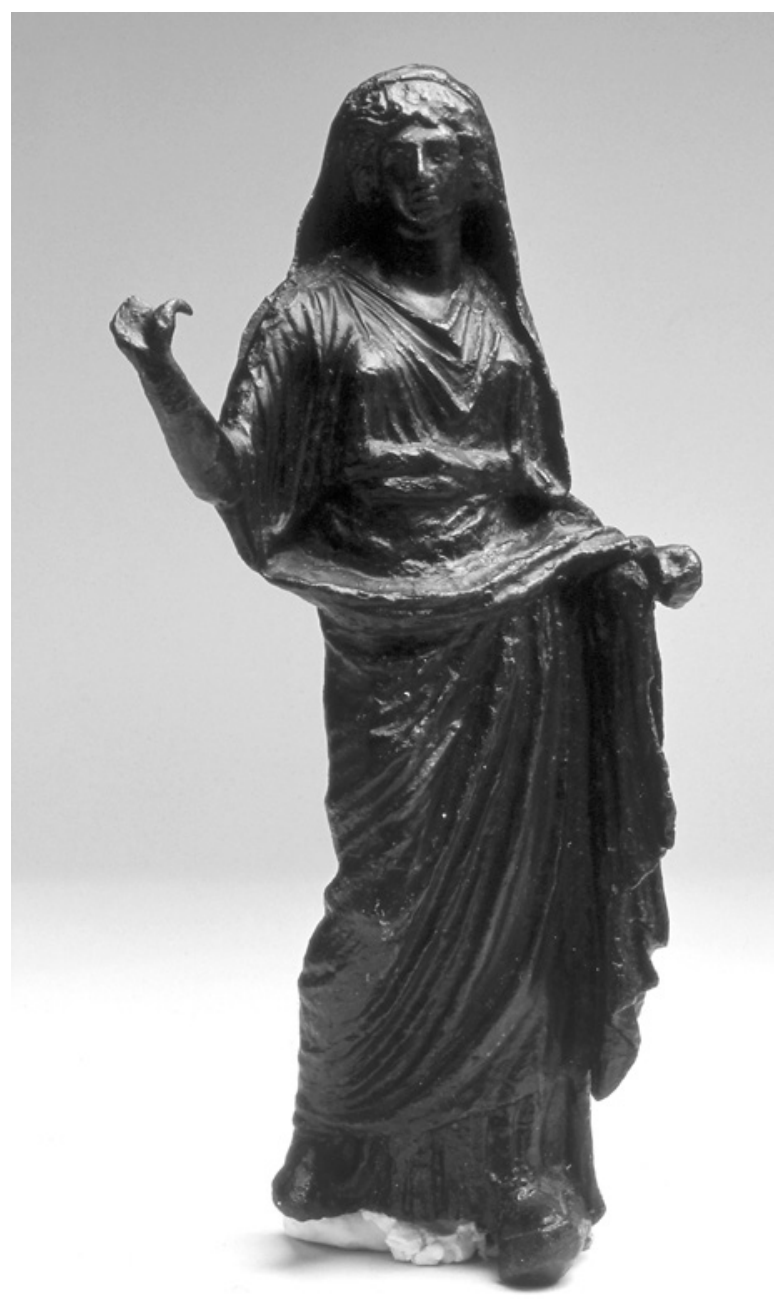

Fig. 3: Figura de bronce con representación de posible flaminica, siglo I d.C. Cerro del Calvario, Mérida (Foto M.N.A.R.).

derecha se alza hasta la altura del hombro y está semiabierta, con el pulgar muy doblado hacia atrás. Esta postura y la concavidad de la palma dan pie a pensar que sostuvo algún objeto hoy desaparecido. De hecho faltan los cuatro dedos que hipotéticamente deberían sujetarlo y que quizás fueron arrancados con él. El gesto más parecido lo hemos encontrado en el retrato de la flaminica africana Minia Procula (Yacoub 1996: 49, fig. 43), que sin embargo parece tener la mano (también sin dedos) simplemente abierta y vacía. De nuevo con la pieza emeritense nos encontramos ante una imagen genérica, imposible de identificar con una sacerdotisa real de nombre conocido aunque sí asociable con una propietaria que ejerciera esa función. 
Sin embargo, por las inscripciones honoríficas podemos asegurar que las imágenes a ellas dedicadas fueron mucho más numerosas de las que conservamos. De hecho, si conocemos a gran parte de las flaminicae y sacerdotes es precisamente por habérseles concedido el honor de una estatua pública o la erección por familiares, libertos u otros allegados de una privada, cuyas dedicatorias y pedestales son hoy los únicos testimonios de su existencia. E. Melchor (2008: 449, n. 23 con las referencias concretas de las inscripciones) precisa algunas cifras para la Bética: quince sacerdotisas que reciben estatuas como honor público, aunque en su opinión la condición sacerdotal por sí sola no implica una dedicación de este tipo. Coincide en esta idea con Mirón (1996: 208-209), para quien sólo se homenajearía con estatuas a las más destacadas de ellas, equiparándolas en el ámbito público con sus homólogos varones. Para las otras dos provincias contamos con otras quince de la Citerior (Mirón 1996: no 8-16, 18-19, 57, 59-61 con sus referencias) y tres más de la Lusitania (Mirón 1996: $\mathrm{n}^{\circ} 5,7,52$ ), entre las de carácter público y las privadas. Evidentemente, en el estado en que conservamos la documentación (pedestales disociados de sus imágenes, falta de contexto de muchas de las piezas, ejemplos aislados de ciudades diferentes) no es posible reconstruir el "paisaje escultórico" de los foros urbanos en los que estas estatuas se disponen ni, por lo tanto, comprobar el impacto visual que producirían las figuras femeninas entre las masculinas, mucho más numerosas. Sin embargo, como simple dato indicativo, podemos mencionar que en Tarraco los pedestales conservados dedicados a sacerdotisas imperiales provinciales y locales son 13 frente a 76 de hombres, excluidos los seviri augustales (datos tomados de Alföldy 1979: 237-239).

Los pedestales y dedicatorias conservados no nos dejan aclarar si las sacerdotisas preferían mostrarse como tales, con algún gesto o atributo cultual, o sólo se retrataban como las matronas de buena familia que efectivamente eran en la mayor parte de los casos. Probablemente muchas de ellas debamos reconocerlas en los numerosos retratos anónimos y los cuerpos y torsos con vestimentas matronales que se conservan en los museos sin otra identificación más precisa, como ya hemos propuesto en el trabajo antes citado (Oria e.p.). Quizás debamos fijarnos particularmente en aquellas que se muestran veladas, entre las que podemos citar como ejemplo dos retratos de Córdoba (publicados por León 2001: 186-187 $n^{\circ} 50,192-193 n^{\circ} 52$ ) y otro saguntino que representa a una anciana (recientemente revisado por Arasa 2010), así como una pieza del siglo I d.C. muy vinculada en su técnica y estilo a las tradiciones artísticas indígenas pero de iconografía ya claramente romana, la llamada "Dama de Puente Genil" (Sociedad ibérica... 1992, 160-161, con referencias anteriores $)^{5}$.

Melchor (2008: 451) considera que algunas pudieron presentarse sub specie deae y cita en concreto el caso de la flaminica perpetua de Barbesula Alfia Domitia Severiana, en cuyo honor se levantó una estatua de plata dedicada a Juno Augusta (IRPC 80). De aceptarse la idea, podrían interpretarse en el mismo sentido otros pedestales de estatuas dedicadas por sacerdotisas hispanas a diversas diosas, como el de Ceres Augusta en memoria de la flaminica provincial de la Bética Quintia Flaccina, en su Munigua natal (AE 1966, $183=$ CILA II.4 1055). En este caso, tratándose de una dedicatoria póstuma, la consecratio in formam deorum sería plausible como expresión del paso a la inmortalidad del espíritu de la difunta, ya que la gran mayoría de las imágenes de esta clase en contexto o sobre soportes claramente significativos son funerarias (v. los casos estudiados en Wrede 1981 o D'Ambra 2000, centrada en las figuras de Venus con retrato individual). Pero no lo es tanto cuando las homenajeadas viven aún, como aparentemente Alfia Domitia Severiana o las dos damas a las que nos referiremos a continuación. En cualquier caso sería interesante, aunque también un tanto arriesgado por lo subjetivo, revisar qué imágenes de diosas conocidas en la Península Ibérica presentan un rostro excesivamente "personal" como para corresponder a la estereotipada idealización de las iconografías divinas. La escultura femenina de bronce procedente de Fuentes de Ebro (Bronces... 1990: 190 n 49) bien podría ser

5. Excluimos aquí los retratos de mujeres de la familia imperial, particularmente Livia velada como signo de su condición de sacerdotisa suprema del culto a Augusto o de su asimilación a una diosa, de los que hay varios ejemplares hispanos: la conocidísima Livia Ceres de Baena en el M.A.N. (EREP n ${ }^{\circ}$ 171, León 2001: 328-331 n ${ }^{\circ}$ 101); la del Museu Machado de Castro de Coimbra, que muestra el hueco para insertar la diadema entre el velo y el cabello (Gonçalves 2007: vol. $179-81 \mathrm{n}^{\circ} 4$ con toda la bibliografía anterior, vol. $214 \mathrm{n}^{\circ}$ 4); la dudosa Drusila del Cortijo de Alcurrucén en la localidad cordobesa de Pedro Abad (León 2001: 340-343 n 104, Garriguet 20022003: 130 ss., Lám. 5 a-b), con velo, corona vegetal y diadema; así como la mujer joven con diadema e infulae conservada en la Hispanic Society de Nueva York (Tesoros HSA 2009: $438 \mathrm{n}^{\circ} 168$ ), de procedencia hispana indeterminada aunque atribuida a Itálica, cuya identificación con Drusila parece contar con mejores argumentos (Wood 1995: 479, Garriguet 2002-2003: 137, Lám. VIIa-b) que la propuesta de García y Bellido (EREP $\mathrm{n}^{\circ} 36$ ) de considerarla una Agripina Menor. En estos casos hay pocas dudas en cuanto a la condición sacerdotal por el papel de estas auténticas "Primeras Damas" a la cabeza del culto imperial, e incluso se pueden justificar sus tocados tras la correspondiente divinización, pero en cambio escapan al análisis de la sociedad provincial que ahora estamos realizando. 
un ejemplo de lo dicho: una figura vestida con túnica ceñida bajo el pecho y tocada con diadema e ínfulas, atributos que pueden identificar a diosas como Juno, combinados con un expresivo rostro propio de un retrato. Su cronología, siglo I a.C., es anterior a la generalización de la práctica que analizamos, la dedicatoria de estatuas públicas a sacerdotisas ciudadanas y la propia proliferación de éstas en relación con el culto imperial. Sin embargo, nos ayuda a imaginar cómo resultaría una estatua honorífica, en uno de los materiales más habituales para ello, en la que una mujer real se presenta ante su comunidad con el aspecto de una diosa.

De todas formas sí podemos apoyarnos en algunos datos indirectos para componer las imágenes perdidas de las sacerdotisas hispanas. Por ejemplo, la flaminica italicense Vibia Modesta dedicó a la Victoria Augusta, entre otras muchas joyas, su corona flaminal de oro adornada con tres cabecitas de diosas igualmente enjoyadas: Isis, Ceres y Juno Reina (Blanco 1983: 8 ss. = CILA II.2 358), precisamente las dos diosas a las que con más frecuencia se asimilan las emperatrices y otra importada en origen pero que no es raro ver denominada Augusta. Probablemente su presencia en esta corona no es casual (Delgado 1998: 76-77). También Lucretia Campana, flaminica de Tucci, incluyó una corona de oro, en este caso como añadido a la estatua de la Piedad Augusta dedicada en el testamento de su padre, que fue flamen provincial y pontífice perpetuo (CIL II 1663). Fuera de Hispania se conocen algunas representaciones de sacerdotisas con coronas semejantes decoradas con pequeños bustos, que nos ayudan a hacernos una mejor idea de su aspecto: la gran escultura de Plancia Magna, sacerdotisa de Cibeles, Ártemis y el culto imperial en Perge durante los primeros años del s. II d.C. (Boatwright 1991), quien luce la corona muy adelantada bajo el velo; y una cabeza de desconocida de época antonina conservada en el Kimbell Art Museum de Fort Worth, Texas, con el no AP 1969, 18 (www.kimbellart.org/Collections), que parece llevarla sobre el mismo. En inscripciones de sacerdotisas se mencionan otras joyas, pero no tenemos seguridad de que sean sus distintivos oficiales o simples adornos personales.

\section{I.4. Las sacerdotisas de cultos orientales}

Los especialistas (por ejemplo Alvar 1986) suelen aludir a la existencia de algunas sacerdotisas de cultos orientales en Hispania, pero poco se puede afirmar de ellas en el terreno iconográfico. Aceptando que

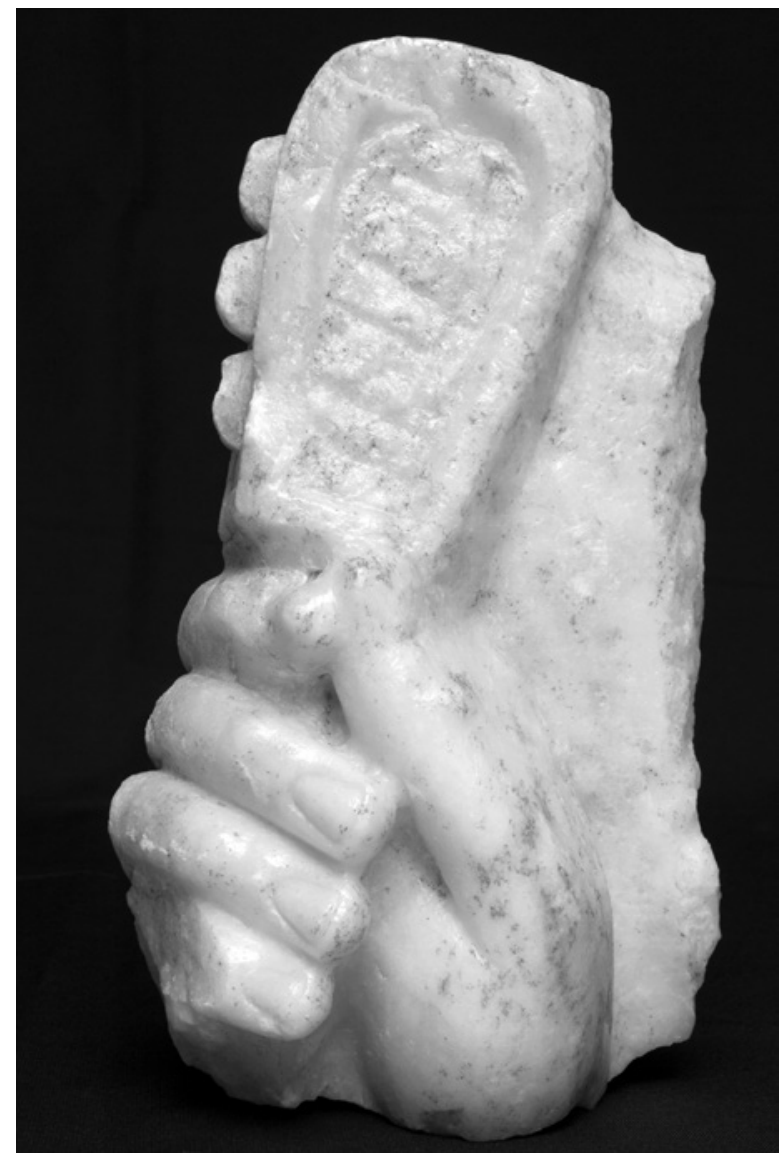

Fig. 4: Mano con sistro, época altoimperial. C/ General Aranda (Reyes Huertas), Mérida (Foto M.N.A.R.).

seguirían la tónica general de identificarse en su aspecto con la propia diosa, debe pertenecer a una sacerdotisa, si no a la misma Isis, un relieve emeritense de fecha imprecisa del que sólo se conserva una mano con el característico sistro (Fig. 4), instrumento musical ligado a los ritos de la diosa (Álvarez Sáez de Buruaga 195557: 212-213). Una cabeza-retrato de época neroniana para insertar en un cuerpo hoy desaparecido, también de Mérida (Fig. 5), ha sido vinculada a los cultos orientales. Los motivos son su cercanía a la Casa del Mitreo y sobre todo su original peinado en tirabuzones, que se relaciona con modelos orientales y en concreto con sacerdotisas de Isis (Nogales 1997: 64-66 n 43, Lám. XXXIX A-D, citando a Traversari 1968: 19). Descartamos en cambio la cabeza que apareció asociada al sistro y que tradicionalmente se ha descrito como una sacerdotisa anciana (García y Bellido 1967: 116, Lám. XII), ya que en realidad representa a un bárbaro (Trillmich 1997: $376, \mathrm{n}^{\circ}$ 145). Podemos recordar que entre las 


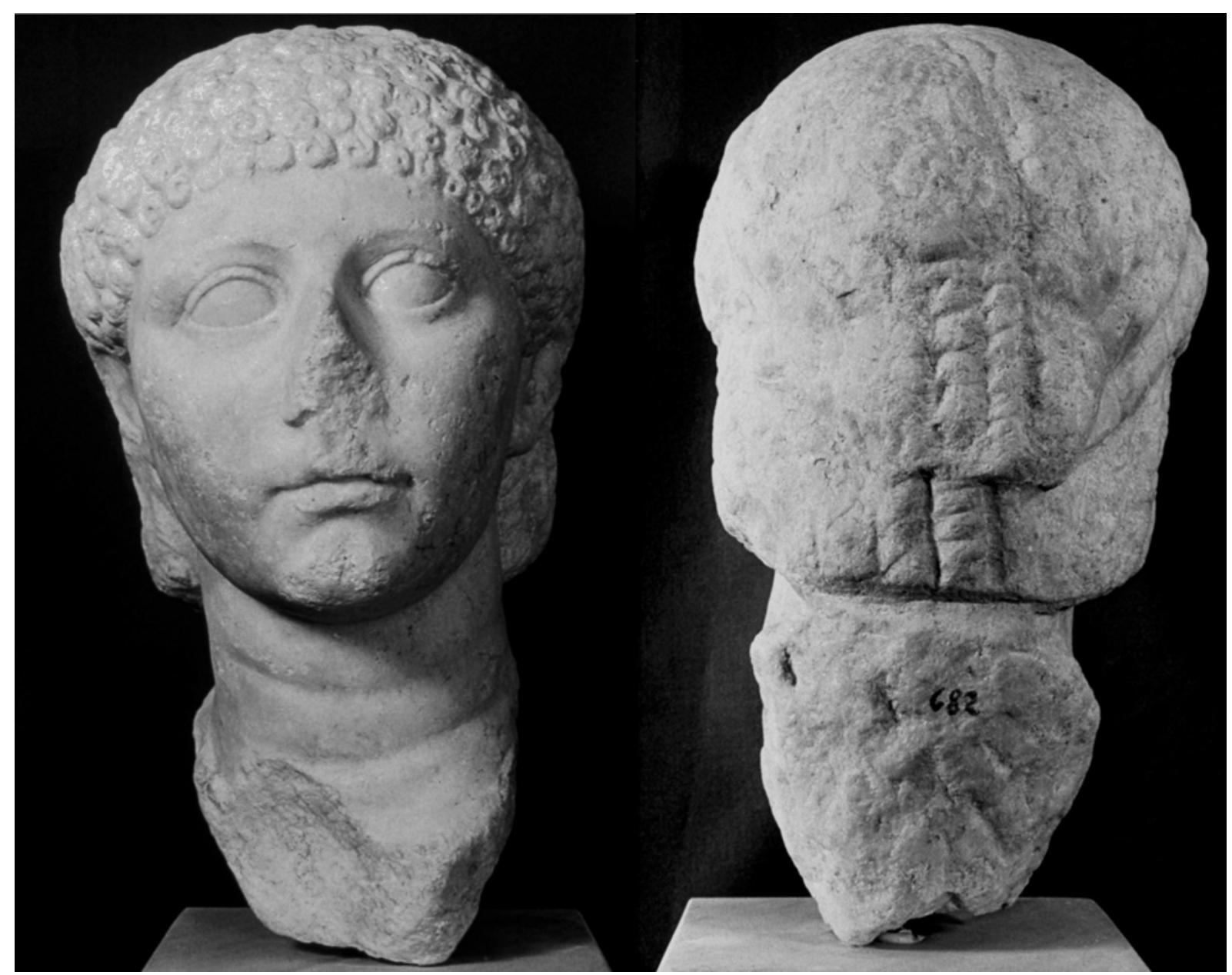

Fig. 5: Retrato de posible sacerdotisa isíaca, mediados del siglo I d.C., Casa del Mitreo, Mérida (Foto M.N.A.R.).

piezas excavadas en el Iseo del teatro de Itálica se encuentra una cabeza de anciana con el cabello recogido y sin ningún tocado o atributo en especial, fechable en el siglo III d.C. (Corzo 1991: 137, Figs. 10-12; Rodríguez 2004: 540 n $^{\circ}$ E-6, Lám. X), aunque desconocemos su relación precisa con el culto: sacerdotisa, auxiliar, simple devota... Otros fragmentos escultóricos del mismo entorno y que reproducen pliegues de ropajes se han relacionado con esculturas de sacerdotisas que adornarían el pequeño recinto cultual (Corzo 1991: 137).

Otras dos presuntas sacerdotisas hispanas de cultos orientales estarían documentadas por epigrafía: una isíaca en Igabrum (CIL II 1611) y una cernófora del culto de Cibeles en Olisipo (CIL II 179). La segunda de ellas no debe ser más que una iniciada orgullosa de su condición, según su título. En cuanto a la primera, su caso despierta más dudas ya que el título podría referirse tanto a una simple iniciada, como a una sacerdotisa. Diversos autores, a los que sigue Delgado (1998: 117, con referencias a los partidarios de una $\mathrm{u}$ otra interpretación), han preferido considerarla como tal debido fundamentalmente a dos hechos: que el nombre del municipio va asociado al del título religioso, lo que sería indicativo de un culto oficial y que la interesada, Flaminia Pale, recibe el honor público de una estatua, característico como ya hemos visto de las sacerdotisas. De nuevo no podemos más que especular con el aspecto de esta imagen, aunque según hemos dicho más atrás, las isíacas suelen mostrarse con la misma vestimenta que su diosa y llevando en las manos elementos cultuales como el sistro, la sítula, una bandeja de ofrendas... El ejemplar del Museo de Palermo ( $\mathrm{n}^{\mathrm{o}} 704$ (N.I. 1515), Sfameni Gasparro 1973: $255 n^{\circ} 195$, Fig. 44) es uno de los más conocidos con esta iconografía, que también presentan el relieve funerario de Cantinea Procla en el Museo de las Termas 
(Eingartner 1991: 160-161 nº 132, Lám. LXXXI) o el griego de Sosibia en el Museum of Fine Arts de Boston ( $\mathrm{n}^{\mathrm{o}}$ 1971.209, www.mfa.org/collections, "Grave stele of Sosibia"), por citar sólo algunos ejemplos muy evidentes.

\section{LAS DEVOTAS}

\section{II.1. La imagen de las devotas hispanas}

Si hay un aspecto de la presencia femenina en la religiosidad hispanorromana mal caracterizado desde el punto de vista iconográfico, son las mujeres como devotas, oferentes, suplicantes, etc. De hecho prácticamente no existen imágenes, a diferencia de lo que ocurre en el mundo prerromano y con especial abundancia en la cultura ibérica, donde los exvotos femeninos alcanzan un alto número al que quizás habría que añadir algunas de las figuras oferentes que mencionábamos antes, con respecto a las sacerdotisas (últimamente, como reflexión general con abundante bibliografía, Prados 2007). Incluso resulta llamativo que en uno de los pocos conjuntos votivos en contexto cultual, un templete en el foro republicano de Sagunto, fechado en un momento de transición en que las tradiciones culturales ibéricas conviven con la progresiva implantación de los esquemas romanos, sólo haya un personaje femenino entre las trece figurillas de bronce de tema dionisíaco (Blecht 1989: 84-88 n 13) y difícilmente pueda considerarse representación de una devota real.

En general el exvoto romano consiste en una inscripción acompañada o no de imágenes, más o menos ricamente decorada según las posibilidades del donante, o en una figurilla de bronce o terracota. Estas últimas muestran con más frecuencia a los propios dioses que a los devotos, o bien representan el beneficio solicitado / recibido de forma genérica, por ejemplo mediante el miembro enfermo sanado. En estos casos sí podemos ver alusiones directas a mujeres, a través de órganos femeninos (Girardon 1993, con ejemplos de la Italia republicana que siguen la tradición itálica y etrusca). Pero esto nos indica en todo caso la preocupación de las mujeres por su salud reproductiva, pero no cómo se ven a sí mismas ante la divinidad.

Un interesante pedestal hispano de época antonina, el de la flaminica barbesulana mencionado más atrás, es quizás la única excepción en esta línea, aunque también sujeta a interpretaciones. Su lateral derecho muestra la figura de una mujer con un niño pequeño en brazos, de

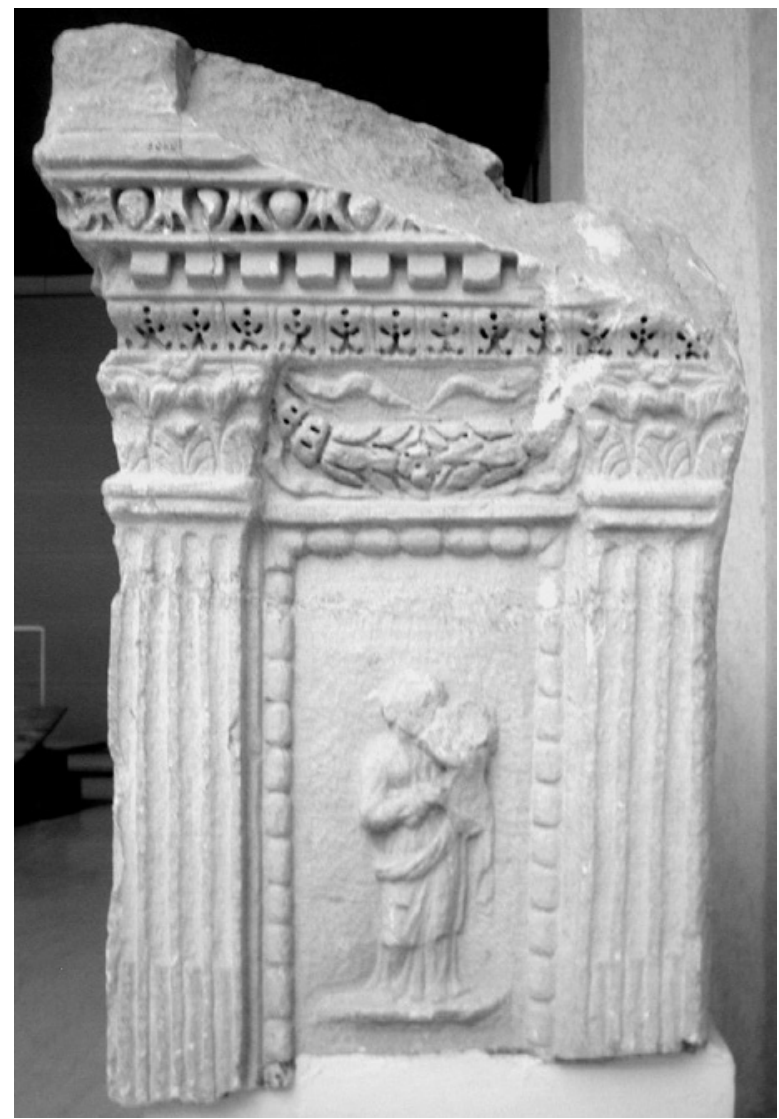

Fig. 6: Lateral derecho del pedestal dedicado a Juno por la flaminica Alfia Domitia Severiana, con escena de maternidad; época antonina, Barbesula (San Roque, Cádiz) (Foto Museo de Cádiz, Junta de Andalucía).

sexo indeterminado porque la cabeza está deteriorada y la vestimenta es poco distintiva. Ella viste las prendas habituales en una matrona y gira la cabeza con un gesto de ternura hacia la criatura que lleva la mano a su barbilla (Fig. 6). No puede considerarse una imagen de la diosa titular de la dedicatoria, Juno Augusta, aunque así aparezca interpretada en la ficha de la pieza en la red digital del Ministerio de Cultura CERES, ni siquiera en su advocación de Lucina la protectora del parto. En efecto, carece de cualquier atributo específico y de paralelos iconográficos, puesto que tanto Juno en su aspecto maternal como Fecunditas aparecen normalmente en las representaciones de esta época (por ejemplo, en RIC III 504, 1634-1639) entronizadas o de pie en actitud solemne, con cetro y coronadas / diademadas, sin establecer una relación tan afectuosa con el o los niños que las rodean. El tono oficial y la fecha aproximada de la inscripción han inducido también 
a considerarla un homenaje a la prolífica emperatriz Faustina la Joven (Rodríguez Oliva 1978: 219-221), similar a los que en las monedas asocian su retrato a una imagen maternal de Fecunditas Augusta (por ejemplo, RIC III 676-679, 1634). La propia Faustina aparece como madre en diversas emisiones monetales (RIC III $719,1636,1673,1675$, etc.). Pero dado que los rasgos están tan difuminados tampoco podemos hablar aquí de retrato imperial, faltando igualmente la alusión específica a la Virtud correspondiente. ¿Por qué no pensar que quien había sido madre fuese la propia flaminica, que manifestara de esta forma su agradecimiento a la diosa y a la vez "presentase en sociedad" a un nuevo miembro de una importante dinastía local? En todo caso, estamos ante una imagen de maternidad que acentúa el aspecto más íntimo y familiar de la misma y nos proporciona al menos un indicio de cómo una devota y reciente madre se dejaría ver ante los dioses.

En realidad la carencia de imágenes no es un rasgo exclusivamente femenino. Tampoco los devotos masculinos de los dioses (y de las diosas) suelen mostrarse ante el público representando ese papel, aunque esto no quiere decir, ni mucho menos, que unas y otros sean invisibles. Lo que significa es que su imagen tendremos que construirla a partir de otras fuentes de información. La epigrafía votiva ${ }^{6}$ es obviamente la que nos proporciona más datos sobre las mujeres: a quiénes veneran y si sus devociones se relacionan con la vertiente pública o con la privada de la religión, aunque la mayor parte de las inscripciones están dedicadas por hombres, incluidas las que se dirigen a las diosas. Este hecho puede explicarse por el mayor papel público en general del hombre y en consecuencia, también sus mayores posibilidades de dejar manifestaciones públicas de su devoción. Sin embargo no tendría por qué afectar al ámbito de la devoción privada, donde el panorama es similar. Las mujeres no ofrecen sus exvotos preferentemente a las diosas, ni son mayoritarias en ningún culto. Por el contrario, son frecuentes las dedicatorias de mujeres a dioses masculinos, entre ellos algunos tan "poco apropiados" como Marte y Hércules, así como Júpiter en su advocación política de Óptimo Máximo. Un dios

6. La base de información es el volumen II del CIL como muestra representativa, aunque completado ocasionalmente con otros catálogos más recientes, en particular los fascículos hasta ahora publicados de la reedición actualizada de $C I L$ II y los diversos volúmenes de CILA, así como la base on line Epigraphische Datenbank Heidelberg $(\mathrm{EDH})$. Como precedente, véase la recopilación que a partir de CIL II realizó A. M ${ }^{a}$ Vázquez Hoys (Vázquez 1982-83), reuniendo tanto información acerca de las divinidades femeninas, como de las devociones propias de las mujeres. sanador como Endovélico es tan venerado por hombres como por mujeres, como les ocurre a las Ninfas, ya que la salud es una preocupación universal. Las hispanas se muestran devotas de las diosas protectoras de la mujer en distintos sentidos, particularmente los de fecundidad y maternidad, pero no sólo. Venus en su faceta política resulta ser la diosa que más dedicatorias de mujeres recibe en Hispania, seguida de Juno. Entre los cultos políticos destaca su preferencia por las Virtudes imperiales, con más insistencia que en otras provincias del Imperio, y entre ellas la favorita es la Piedad Augusta. En el mismo ambiente cultual, Mirón (1996: III Parte, esp. 239) indica que las dedicatorias a divinidades Augustas realizadas exclusivamente por mujeres son en Hispania un $17^{\prime} 02 \%$, a las que sumar un $9^{\prime} 57 \%$ en que aparecen asociadas a hombres. Esto supone el porcentaje más alto de participación de mujeres de todas las provincias occidentales. En cuanto a las diosas indígenas, la actitud de las hispanas no es uniforme y depende en gran medida de su carácter y atribuciones.

La epigrafía nos deja también la voz en primera persona de las devotas, y esa voz suele ser relativamente baja y discreta con pocas excepciones. Las mujeres se limitan a darnos su nombre, indistintamente solas o acompañadas de parientes masculinos, esposos, padres, hijos y hermanos y también de sus patronos. La vinculación al grupo familiar y en particular a los varones casi siempre se pone de manifiesto, aunque en algunas regiones como la Meseta Norte parece ser excepcional y minoritaria (Gallego 2004: 70-71, aunque más interesada en cuestiones de indigenismo / romanización que en expresiones de feminidad). En algún caso el protagonismo de él oscurece totalmente a la devota que lo acompaña, como ocurre en una dedicatoria de Tarraco a Minerva Augusta cuyos responsables son simplemente Mercurius et mulier (CIL II 4084). Por contra, muchas veces son ellas quienes se hacen cargo de la dedicatoria en nombre de este familiar o patrono vivo o ya fallecido. Suelen mostrar poca originalidad al expresar su devoción, eligiendo las fórmulas del repertorio habitual, de modo que no se esfuerzan por presentarse como especialmente piadosas salvo en ciertas circunstancias. Como hacen los hombres, cuando su dedicatoria tiene lugar en el marco de los cultos cívicos (en agradecimiento de un sacerdocio propio o de un familiar cercano, en respuesta a un homenaje público, etc.) añaden el título de Augustas a las divinidades de su elección y suelen extenderse en los motivos y circunstancias de la ofrenda. En este ambiente la ostentación se hace casi obligada y afecta tanto al aspecto lujoso de los exvotos y las inscripciones que los conmemoran, como a 
la visión que de sí mismas ofrecen las dedicantes. De paso estas dedicatorias nos muestran el poder económico de un reducido grupo de mujeres que no sólo dispone de grandes sumas, sino de libertad para gastarlas. Podemos destacar que mientras los templos y esculturas son donados indistintamente por hombres y mujeres, la dedicación de joyas para adornar las imágenes de diosas parece ser una práctica exclusiva de mujeres, que honran públicamente a sus diosas preferidas tal y como ellas mismas se presentan a la comunidad (v. Hoyo 1994). Cuando se trata de exvotos privados suelen limitarse a su nombre, el de la divinidad en cuestión y las fórmulas de consagración y cumplimiento de la promesa, añadiendo el nombre de los beneficiarios de la petición a los dioses cuando se trata, por ejemplo, de una promesa por la salud o en honor de otra persona.

\section{CONCLUSIÓN: IMÁGENES Y ROLES FEMENINOS EN EL ÁMBITO RELIGIOSO DE LA HISPANIA ROMANA}

Lo que las imágenes nos transmiten acerca de la mujer en el ámbito religioso y en la sociedad hispana puede concretarse en varios aspectos, aunque desde el punto de vista iconográfico la información queda un tanto distorsionada:

- Las diosas, en particular las del panteón clásico, son con mucho las más representadas (de nuevo remitimos a Oria 2011) y lo que transmite su iconografía es un concepto idealizado de la belleza femenina, una atención a la imagen propia traducida en vestimentas adecuadas, cuidadosos tocados, joyas, etc. que podemos reconocer también en las mujeres con más posibilidades económicas. En cambio en los que podríamos llamar atributos funcionales, los objetos y las actitudes que reflejan sus poderes en un campo determinado, no se trasluce una preferencia por lo específicamente femenino. La imagen de feminidad que transmiten resulta un tanto tópica y refleja sólo parcialmente la situación real de las mujeres en el ámbito religioso.

- Las sacerdotisas debieron ser en su momento abundantes y gozaron de visibilidad pública, aunque en la mayor parte de los casos hoy sólo tengamos una referencia indirecta de sus imágenes.

- En cuanto a las mujeres como devotas, no nos han transmitido más imagen de sí mismas y de sus actitudes que la que podemos deducir por el contenido de sus dedicatorias y el aspecto de los soportes: ostentosa en los grandes exvotos públicos de las damas más pudientes, discreta en los exvotos privados, casi siempre vinculada a los varones de su familia.

En realidad, dado el carácter de la práctica religiosa y cultual, tampoco tiene por qué sorprendernos esta situación. La divinidad objeto de culto debe mostrarse ante el devoto con la máxima claridad y eficacia a la hora de facilitar su reconocimiento, mostrar sus atribuciones y su poder y conmover a sus devotos. Los sacerdotes, como oficiantes de las ceremonias cultuales, están situados en el punto de mira de la comunidad, adquiriendo una gran relevancia social a ojos de ésta. El papel propio de las mujeres en los cultos públicos, como sacerdotisas y como responsables de riquísimas donaciones, es bastante más activo de lo que habitualmente se ha dicho. Además las sacerdotisas tienen una elevada visibilidad en sus respectivas ciudades, aunque a falta de la mayoría de las estatuas dedicadas, no podamos saber si destacaba precisamente su faceta sacerdotal o la mera confirmación de su status social a través de sus retratos. Por el contrario los seguidores del culto, sean hombres o mujeres, se perciben como un colectivo más o menos indiferenciado desde el punto de vista de las manifestaciones públicas, mientras que desde el privado, cada devota establecerá sus propias pautas de relación con las divinidades, siempre desde una posición de humildad ante su poder, aunque no necesariamente ante el resto de la comunidad.

\section{BIBLIOGRAFÍA}

\section{Abreviaturas de repertorios y catálogos}

Bronces... (1990): Los bronces romanos en España. Catálogo de la Exposición. Madrid, Ministerio de Cultura.

CIL II: HÜBNER, E. (1869 y 1892): Corpus Inscriptionum Latinarum, vol. II. Inscripciones Hispaniae Latinae y Vol. II, Supplementum. Berlín, Academia de las Ciencias.

CILA II.2: GONZÁLEZ, J. (1991): Corpus de Inscripciones Latinas de Andalucía, vol. II: Sevilla. Tomo II: La Vega (Itálica). Sevilla, Consejería de Cultura y Medio Ambiente.

CILA II.4: GONZÁLEZ, J. (1996): Corpus de Inscripciones Latinas de Andalucía, vol. II: Sevilla. Tomo IV: El Aljarafe, Sierra Norte, Sierra Sur. Sevilla, Consejería de Cultura y Medio Ambiente.

EREP: GARCÍA Y BELLIDO, A. (1949): Esculturas romanas de España y Portugal. Madrid, C.S.I.C. 
IRPC: GONZÁLEZ, J. (1982): Inscripciones romanas de la provincia de Cádiz. Cádiz, Diputación Provincial.

RIC III: MATTINGLY, H.-SYDENHAM, E. A. (1930): The Roman Imperial Coinage. Vol. III: Antoninus Pius-Commodus. Londres, Spink \& Son.

Sociedad Ibérica... (1992): VV.AA.: La sociedad ibérica a través de la imagen. Catálogo de la Exposición (Albacete-Murcia-Valencia-Badajoz, $1992-$ 1993). Madrid, Ministerio de Cultura.

Tesoros HSA (2009): VV.AA.: El tesoro arqueológico de la Hispanic Society of America, Catálogo de la Exposición (Sevilla, mayo-junio 2009). Sevilla, Fundación Cajasol-Hispanic Society of AmericaMuseo Arqueológico Regional de la Comunidad de Madrid.

\section{Monografías y artículos}

ALFÖLDY, G. (1979): "Bildprogramme in den römischen Städten des Conventus Tarraconensis - Das Zeugnis der Statuenpostamente", Homenaje a García y Bellido IV. Revista de la Universidad Complutense XVIII - 118: 177-275.

ALVAR, J. (1986): "Las mujeres y los misterios en Hispania", Actas de las Quintas Jornadas de Investigación interdisciplinaria: La mujer en el mundo antiguo, Madrid, Instituto Universitario de Estudios de la Mujer: 245-257.

ÁLVAREZ SÁEZ DE BURUAGA, J. (1955-57): Memorias de los Museos Arqueológicos Provinciales XVI-XVIII. Madrid, Aldus.

ARASA, F. (2010): "Novedades en la escultura del País Valenciano", en J. M. Abascal y R. Cebrián (eds.): Escultura romana en Hispania VI. Homenaje a Eva Koppel. Actas de la VI Reunión de Escultura Romana en Hispania (Segóbriga 2008). Murcia, Tabularium.

ARCE, J. y BURKHALTER, F. (coords.) (1993): Bronces y religión romana. Actas del XI Congreso Internacional sobre Bronces Antiguos (Madrid, 1990). Monografías de la Escuela Española de Historia y Arqueología, Roma. Madrid, CSIC.

BENDALA, M. (2007): "La Dama de Baza: el modelo de la dama sedente, su contexto y su problemática", en T. Chapa e I. Izquierdo (2007): 171-181.

BERT LOTT, J. (2004): The neighbourhoods of Augustan Rome. Cambridge, Cambridge University Press.

BLANCO FREIJEIRO, A. (1983): "Nuevas inscripciones latinas de Itálica”, BRAH CLXXX: 1-15.
BLECH, M. (1989): "Republikanischen Bronzestatuetten aus Sagunt", Homenatge A. Chabret, 18881988: 43-91. Valencia, Generalitat Valenciana.

BOELS-JANSSEN, N. (1993): La vie religieuse des matrones dans la Rome archaïque. Col. de l'École Française de Rome n ${ }^{\circ} 176$. Roma, École Française.

BONIFACIO, R. (1997): Ritratti romani da Pompeii. Perugia, Università di Perugia.

BRUIT-ZAIDMAN, L. (1991): "Las hijas de Pandora. Mujeres y rituales en las ciudades", en G. Duby y M. Perrot (dirs.), Historia de las mujeres. I. La Antigüedad. Madrid, Altea-Taurus-Alfaguara: 373-419.

CHAPA, T. (1997): "Sculptures", en P. Rouillard: Antiquités de l'Espagne. París, Réunion des Musées Nationaux: 58-70.

- (2006): "Sacrificio y sacerdocio entre los iberos", en J. L. Escacena y E. Ferrer (eds.), Entre Dios y los hombres: el sacerdocio en la Antigüedad, Spal Monografías VII. Sevilla, Servicio de Publicaciones de la Universidad de Sevilla: 157-180.

CHAPA, T. e IZQUIERDO, I. (coords.) (2007): La Dama de Baza. Un viaje femenino al Más Allá. Madrid, Ministerio de Cultura.

CHAPA, T. y MADRIGAL, A. (1997): "El sacerdocio en época ibérica", Spal 6: 187-203. http://dx.doi. org/10.12795/spal.1997.i6.11

CORZO, R. (1991): "Isis en el teatro de Itálica", Boletín de Bellas Artes 19, pp. 123-148.

CORZO, R. y TOSCANO, M. (2003): Excavaciones en el teatro de Itálica, vol. III: 1990. Sevilla, Junta de Andalucía.

CRISTOFANI, M. (1985): I bronzi degli Etruschi. Novara, Istituto Geografico de Agostini.

D'AMBRA, E. (2000): "Nudity and adornment in female portrait sculpture of the second century A.D.", en D. E. E. Kleiner y S. B. Matheson (eds.): I, Claudia, II. Women in Roman art and society. Austin, University of Texas Press: 101-114.

DELGADO, J. A. (1998): Élites y organización de la religión en las provincias romanas de la Bética y las Mauritanias: sacerdotes y sacerdocios. B.A.R. International Series $n^{\circ} 724$. Oxford, Oxford University Press.

EINGARTNER, J. (1991): Isis und ihre Dienerinnen in der Kunst der römischen Kaiserzeit. Leiden-Nueva York, Brill.

FERNÁNDEZ MIRANDA, M. y OLMOS, R. (1987): "El timiaterio de Albacete", AEspA 60: 211-219.

FLORY, M. B., 1988 (1997): "The meaning of Augusta in the Julio-Claudian period", American Journal of Ancient History 13.2: 113-138. 
GALLEGO, H. (2004): "La mujer en las estructuras religiosas de Hispania septentrional. Consideraciones en base a la epigrafía votiva hispanorromana del territorio castellano-leonés", Ilu 9: 69-89.

GARCÍA y BELLIDO, A. (1943): La Dama de Elche y el conjunto de piezas arqueológicas reingresadas en España en 1941. Madrid, CSIC.

- (1967): Les religions orientales dans l'Espagne romaine. Leiden, Brill.

GARCÍA ROZAS, R. y ABÁSOLO, J. A. (1993): "Bronces romanos del Museo de Zamora", en J. Arce y F. Burkhalter (coords.) (1993): 171-196.

GARRIGUET, J. A. (2002-2003): "Los retratos imperiales romanos del Cortijo de Alcurrucén (Pedro Abad, Córdoba): ¿testimonios de un grupo estatuario julio-claudio?", $A A C$ 13-14: 119-145.

GIRARDON, S. (1993): "Ancient medicine and anatomical votives in Italy", Institute of Archaeology Bulletin 30: 29-40.

GONÇALVES, L. J. R. (2007): Escultura romana em Portugal: uma arte do quotidiano. Studia Lusitana 2. Mérida, M.N.A.R.

HEMELRIJK, E. A. (2006): "Imperial priestesses, a peliminary survey", en L. De Blois, P. Funke y J. Hahn: The impact of Imperial Rome on religions, ritual and religious life in the Roman Empire: Proceeding of the Fifth Workshop of the International Network "Impact of the Empire" (Roman Empire, 200 B.C. - A.D. 476) (Münster, 30 junio -4 julio 2004). Leiden, Brill: 179-193.

HÖLSCHER, T. (1994): Monumenti statali e pubblico. Roma, L'Erma di Bretschneider.

HOYO, J. del (1994): "Joyas en la Andalucía romana. Documentación epigráfica", Actas del II Congreso de Historia de Andalucía (Córdoba 1991). Córdoba, Junta de AndalucíA: 419-429.

- (2003): "El sacerdocio femenino, medio de integración de la mujer en las estructuras municipales de gobierno", en S. Armani, B. Hurlet-Martineau y A. U. Stylow (eds.), Epigrafia y sociedad en Hispania durante el alto imperio: estructuras y relaciones sociales. Actas de la mesa redonda (Alcalá de Henares, 10-11 de abril de 2000): 129-140. Alcalá de Henares, Casa de Velázquez - Universidad de Alcalá de Henares.

JIMÉNEZ, A. Ma (2006): "La mano de Eva: las mujeres en el culto fenicio-púnico", en J. L. Escacena y E. Ferrer (eds.), Entre Dios y los hombres: el sacerdocio en la Antigüedad, Spal Monografías VII. Sevilla, Servicio de Publicaciones de la Universidad de Sevilla: 83-102.
LEÓN, P. (2001): Retratos romanos de la Bética. Catálogo de la Exposición (Sevilla, 2001). Sevilla, Fundación El Monte.

LIPINSKI, E. (1992): "Prostitution sacrée", Dictionnaire de la Civilisation Phénicienne et Punique: 114-115. Brepols, Turnhout.

LORAUX, N. (1991): “¿Qué es una diosa?”, en G. Duby y M. Perrot (dirs.), Historia de las mujeres. I. La Antigüedad: 29-69. Madrid, Altea-Taurus-Alfaguara.

MARÍN, Ma C. (2000-2001): "La representación de los dioses en el mundo ibérico", Lucentum XIX-XX: 183-198.

MELCHOR, E. (2008): "Mujer y honores públicos en las ciudades de la Bética", en C. Berrendoner, M. Cébeillac-Gervasoni y L. Lamoine (dirs.), Le quotidien municipal dans l'Occident Romain (Clermont-Ferrand-Chamalières, 2007): 443-457. Col. Histoires Croisées. Clermont-Ferrand, Presses Universitaires Blaise-Pascal.

MÉLIDA, J. R. (1925): Catálogo Monumental de España. Provincia de Badajoz. Madrid, Ministerio de Instrucción Pública y Bellas Artes.

MIKOCKI, T. (1995): Sub specie deae. Les impératrices et princesses romaines assimilées à des déesses. Étude iconologique. Roma, Giorgio Bretschneider.

MONEO, T. (2003): Religio Ibérica: santuarios, ritos $y$ divinidades (siglos VII-I a.C.). Madrid, Real Academia de la Historia.

NEGRI SCAFA, P. (2001): "Aspetti del sacerdozio femminile nel Vicino Oriente antico e nel mondo miceneo", en S. Ribichini, M. Rocchi y P. Xella (eds.): La questione delle influenze vicino-orientali sulla religione greca: 389-401. Roma, CNR.

NICOLINI, G. (1998): "Les bronzes figurés ibériques: images de la classe des prêtes", Actas del Congreso Internacional "Los Iberos, Príncipes de Occidente. Estructuras de poder en la sociedad ibérica": 245255. Barcelona, Fundación La Caixa.

NOGALES, T. (1997): El retrato privado en Augusta Emerita. Col. Arte / Arqueología 2. Badajoz, Diputación Provincial, Junta de Extremadura.

ORIA, M. (2011): "Imágenes de feminidad en la religión hispanorromana: las diosas”, en P. Fernández Uriel e I. Rodríguez López (eds.): Iconografía y sociedad en el Mediterráneo antiguo. Homenaje a la Profesora Pilar González Serrano, Signifer n ${ }^{\circ} 36$ : 371-386, Madrid - Salamanca, 2011.

ORIA, M. (e.p.): "De mujeres y sacrificios: un estudio de visibilidad", Salduie 10: 1-21.

PRADOS, L. (1997): "Los ritos de paso y su reflejo en la toréutica ibérica”, en R. Olmos y J. A. Santos 
(eds.), Iconografía ibérica, iconografía itálica: propuestas de interpretación y lectura. Coloquio Internacional (Roma 1993). Serie Varia 3: 273-282. Madrid, Universidad Autónoma de Madrid.

PRADOS, L. (2007): “Mujer y espacio sagrado: Haciendo visibles a las mujeres en los lugares de culto de época ibérica", Complutum 18: 217-225.

RIBICHINI, S. (2004): “Al servizio di Astarte. Ierodulia e prostituzione sacra nei culti fenici e punici", en A. González Blanco, G. Matilla y E. Egea (eds.), El mundo púnico. Religión, antropología y cultura material. Estudios Orientales 5-6: 55-68. Murcia, Universidad de Murcia.

RODRÍGUEZ, O. (2004): El teatro romano de Itálica. Estudio arqueoarquitectónico. Madrid, Universidad Autónoma de Madrid - Fundación Pastor.

RODRÍGUEZ OLIVA, P. (1978): "Municipium Barbesulanum", Baetica 1: 207-233.

SCHEID, J. (1991): "Extranjeras indispensables. Las funciones religiosas de las mujeres en Roma", en G. Duby y M. Perrot (dirs.): Historia de las mujeres. I. La Antigüedad: 421-461. Madrid, Altea-Taurus-Alfaguara.

SCHULTZ, C. E. (2006): Women's religious activity in the Roman Republic. Chapel Hill, The University of North Caroline Press.

SERRANO, J. y MORENA, J. A. (1988): “Un relieve de baja época ibérica procedente de Torreparedones
(Castro del Río-Baena, Córdoba)", AEspA 61: 245-248.

SFAMENI GASPARRO, G. (1973): I culti orientali in Sicilia, E.P.R.O. Leiden, Brill.

TRAVERSARI, G. (1969): Museo Archeologico di Venezia. I ritratti. Roma, Istituto Poligrafico dello Stato.

TRILLMICH, W. (1997): "El modelo de la metrópoli”, en Hispania romana. De tierra de conquista a provincia del Imperio. Catálogo de la Exposición (Roma, 1997): 131-141. Roma, Quasar.

VÁZQUEZ, A. Ma (1982-83): "La mujer en la epigrafía religiosa hispanorromana", CuPAUAM 9-10: 107-150.

VERMASEREN, J. (1977): Corpus Cultus Cybelae Attidisque, vol. III. Leiden, Brill.

WOOD, S. E. (1995): "Diva Drusilla Panthea and the sisters of Caligula”, AJA 99: 457-482.

WOOD, S. E. (1999): Imperial women. A study in public images, $40 B C-A D$ 68. Leiden-Boston-Colonia, Brill.

WREDE, H. (1981): Consecratio in formam deorum. Vergöttliche Privatpersonen in der römischen Kaiserzeit. Mainz, Philip von Zabern.

YACOUB, M. (1996): Le Musée du Bardo (Départements antiques). Túnez, Agence Nationale du Patrimoine. 